\title{
Effects of Motor Coordinative Ability of Male kabaddi Players Playing Surface Clay And Mat
}

BRIJESH KUMAR

ASSISTANT PROFESSOR PHYSICAL EDUCATION

DR SHYAMA PRASAD MUKHERJEE

GOVT DEGREE COLLEGE

DIST-BHADOHI

Mail brijeshmgkvp@gmail.com

\begin{abstract}
The Present study was conducted to find out the impact of playing surface. Clay \& met motor coordinative ability of male state kabaddi players, to conduct the study, 70 male kabaddi player's age group 18-25 years. Who took part in state level kabaddi tournament, eared selected as sample. The selection of subjects was done from players of such teams who stood in top four places of state tournament in Chhattisgarh. Agility of the selected male kabaddi players was assessed by shuttle run test item of cooper's motor fitness test this test is performed twice by the subject i.e. on clay \&met surface respectively. Results indicate the shuttle run performance of male kabaddi on clay surface was significantly better as compared to met surface at .01 level of statistical significance. It was concluded that playing surface effect motor coordinative ability of male kabaddi players.
\end{abstract}

\section{INTRODUCTION}

The surfaces on which athletes run on can play a vital role in determining how well they perform. it has been documented that skill acquisition on different playing 
surface requires a look practice. Kabaddi is a sport which is extremely popular in India in majority of tournaments is still conducted on clay fields whereas state and interstate tournament requires soft mat. Hence the Indian kabaddi players on variety of surfaces which have different frication and traction. Since slight adjustment in terms of frication and traction is required on various surfaces hence the same applies for kabaddi players also. Being a popular sports all over the world these days, so many researchers such as singh and singh, and many others have studied various factors which affect kabaddi performance but so far agility which is the important motor coordinative variable as far as kabaddi performance is concerned has not been assessed in relation to different playing surfaces. In the view of above the researcher decided to find out the impact of playing surface on motor coordinative ability of male kabaddi players. It was also hypothesized that the agility of female kabaddi players will be significantly influence by playing surface mat and clay.

\section{METHODOLOGY}

\section{SAMPLE}

To conduct the study. $(\mathrm{N}=70)$ male kabaddi players age group 18-25 years . who took part in state level kabaddi tournaments were selected randomly . The age range of the subject was 18-25 years.

\section{TOOLS: MOTOR COORDINATIVE ABILITY}

To assess agility of the selected subject's shuttle run test item of cooper's motor fitness test (1974) was used. The motor coordinative ability scores the subjects were ascertained by their shuttle run timings: hence lower the timing, higher the motor coordinative ability formula is used. 


\section{PROCEDURE}

A prior consent was obtained from concerned permission to conduct this study. The subjects were assured that the data will be used for research purpose only and it will be kept confidential. Shuttle run test was performed twice by a subject i,e. on clay and mat surface under the supervision of researcher.

\section{RESULTS AND DISCUSSION}

To compare agility of male state kabaddi players $(\mathrm{N}=70)$ sample ' $\mathrm{t}$ ' test was used. Analysis of data is presented in table 1 and depicted in figure 1.

Comparison of Shuttle run timings of Male Kabaddi Players On Clay and Mat Surface $(\mathrm{N}=70)$ N=70 Male State Players

\begin{tabular}{|l|l|l|ll|l|l|l|}
\hline Variable & Clay & $\begin{array}{l}\text { Mean } \\
18.00\end{array}$ & $\begin{array}{l}\text { Std. } \\
1.19\end{array}$ & Deviation & M. Deviation & "t" & df \\
\hline $\begin{array}{l}\text { Shuttle- } \\
\text { run }\end{array}$ & Mat & Mean & Std. & Deviation & -0.35 & 1.34 & 78 \\
\hline
\end{tabular}

Significant at. 01 level

A perusal of statically analysis reported in table1 shows that mean shuttle run timings of male kabaddi players on clay surface was $\mathbf{1 8 . 0 0}$ while mean time on met surface was $\mathbf{1 8 . 3 5}$ the mean difference of $\mathbf{- 0 . 3 5}$ on clay and mat surface on shuttle run performance indicate that agility of male kabaddi on clay surface was significantly better as compared to mat surface at. 01; level; of statistical significance $(\mathbf{t}=\mathbf{1 . 3 4})$ conform this statement. 

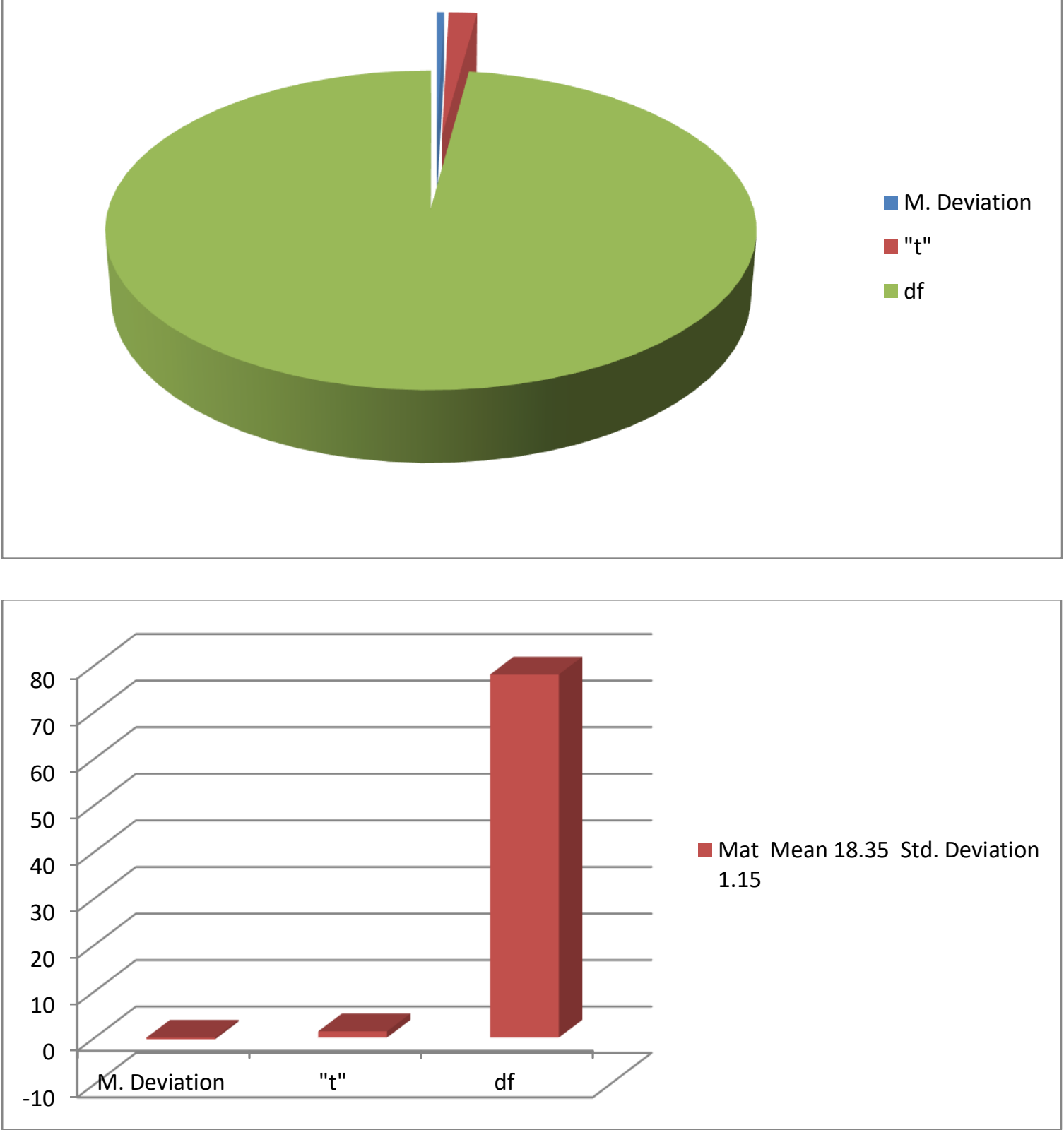

\section{DISCUSSION}

On the basis of analysis, it is observed that it is difficult to adapt to different playing surface for a male kabaddi players when a kabaddi players made transition from clay to mat surface, the un- adapt ability of friction /traction hinders per furnace because coefficient of friction between foot and surface changes from clay to mat . In this perspective the results of the present study are not at all surprising. 


\section{CONCLUSION}

On the basis of results, it may be concluded that playing surface i.e. clay and mat state level players do influence motor coordinative ability of male kabaddi state level players is compromised while playing on met surface as compared to clay playfield.

\section{REFERENCES}

- Cooper Motor Fitness Test (1974). Measurements in Physical Education, Carlton R. Meyers, 2nd Edition, the Ronal Press Company, New York.

- Jaipal and Siwach, R.A. (2013). A Study of Personality Characteristics Young Kabaddi Players of Navodaya Vidyalaya Samiti, India, Research Journal of Physical Education Sciences, vol. (3), 1-4,pp. 1-4.

- Singh, R. and Singh, H. (2013). An evaluation of Selected Physical Fitness variables of Kabaddi, Kho-kho and Wrestling players from Haryana and Punjab, India. Research journal of Physical Education Sciences, Vol, 1(2), 14.

- Mukesh and Mahesh Kumar (20013). A Comparative Study of Co-Ordinate Abilities of Kabbadi and Kho-kho Female Players at College Level. 